\title{
Ignition Target Fabrication and Fielding for the National Ignition Facility
}

T. P. Bernat, H. Huang, A. Nikroo, R. Stephens, H. Wilkens, H. Xu, P. Armstrong, R. Cook, B. Kozioziemski, S. Letts, E. Mapoles, J. Moody, M. McElfresh, J. Sanchez, R. Seugling, J. Cooley, D. Montgomery, A. Nobile

October 18, 2005

2005 Fourth International Conference on Inertial Fusion Sciences and Applications Biarritz, France September 4, 2005 through September 9, 2005 
This document was prepared as an account of work sponsored by an agency of the United States Government. Neither the United States Government nor the University of California nor any of their employees, makes any warranty, express or implied, or assumes any legal liability or responsibility for the accuracy, completeness, or usefulness of any information, apparatus, product, or process disclosed, or represents that its use would not infringe privately owned rights. Reference herein to any specific commercial product, process, or service by trade name, trademark, manufacturer, or otherwise, does not necessarily constitute or imply its endorsement, recommendation, or favoring by the United States Government or the University of California. The views and opinions of authors expressed herein do not necessarily state or reflect those of the United States Government or the University of California, and shall not be used for advertising or product endorsement purposes.

This work was performed under the auspices of the U.S. Department of Energy by University of California, Lawrence Livermore National Laboratory under Contract W-7405-Eng-48. 


\title{
Ignition Target Fabrication and Fielding For the National Ignition Facility
}

\author{
T.P. Bernat, H. Huang, A. Nikroo, R.B. Stephens, H.L. Wilkens, and H. Xu \\ General Atomics, P.O. Box 85608, San Diego, California 92186-5608 \\ P. Armstrong, R. Cook, B. Kozioziemski, S. Letts, E. Mapoles, J. Moody, \\ M. McElfresh, J. Sanchez, and R. Seugling \\ Lawrence Livermore National Laboratory, P.O. Box 808, Livermore, California 94551 \\ J. Cooley, D. Montgomery, and A. Nobile \\ Los Alamos National Laboratory, P.O. Box 1663, Los Alamos, New Mexico 87545
}

\begin{abstract}
Continued advances in the design of ignition targets have stimulating new development paths for target fabrication, with potentially important simplifications for fielding cryogenic ignition targets for the National Ignition Facility. Including graded dopants in ablators as well as optimizing capsule and fuel layer dimensions increase implosion stability. This has led to developments of micron-scale fill tubes to fill and field the targets. Rapid progress has been made in development of the graded dopant layers in capsules as well as their characterization, in fabrication methods for micro-fill-tubes, and in fuel fill control with these fill tubes. Phase-contrast x-ray radiography has allowed characterization of fuel layers in beryllium targets. This target development program includes participation from General Atomics, Lawrence Livermore National Laboratory, and Los Alamos National Laboratory.
\end{abstract}

\section{INTRODUCTION}

The past several years have seen important changes to the design and fielding options of baseline indirectdrive ignition targets for the National Ignition Facility (NIF) presently under construction at Lawrence Livermore National Laboratory [1,2]. Both beryllium and polymer fuel capsules include dopants with radial gradients $-\mathrm{Cu}$ in the case of beryllium and $\mathrm{Ge}$ in the case of polymers. Beryllium has been preferred as an ablator, but until recently there had been concern from the inertial confinement fusion (ICF) community because there was not an identified method for characterizing the solid fuel layer interior to the beryllium capsule. At the time of the last IFSA meeting (2003), x-ray phase contrast radiography was just starting to be explored as a possible characterization tool for the fuel. As well, the ignition target systems for filling, cooling to cryogenic temperatures, delivering to the NIF experiment area, forming and characterizing he fuel layer, and supporting the cryogenic targets in the NIF target chamber were complex and expensive. Micro-fill-tubes were beginning to be developed and tested as a way to fill the capsules with the deuterium-tritium (DT) fuel. This considerably simplifies the support 
system requirements and engineering, and reduces costs, but potentially with some added risk for capsule implosion because of the perturbing presence of the fill tube. And finally, "cocktail" hohlraums, comprising mixtures of gold and other mid-to-high atomic number elements have become baseline. These hohlraums increase the conversion efficiency of high-intensity laser light to the $\mathrm{x}$-rays that implode the ignition capsules. In this paper we review the progress and status of these developments.

\section{GRADED DOPANT CAPSULES}

A Cu-doped beryllium capsule designed for a $1 \mathrm{MJ}$ total energy pulse from the NIF laser is shown in Fig. 1. The radial dopant concentration gradient is not continuous, but stepped, with the highest concentration of $\mathrm{Cu}$ being $0.7 \%$ atomic. The outer portion of the capsule is undoped. The advantage of the graded doping is that it increases the acceptable amplitudes of surface Legendre modes on the capsule exterior for mode numbers greater than about 10 while maintaining the "ignition margin" at a given yield [1].
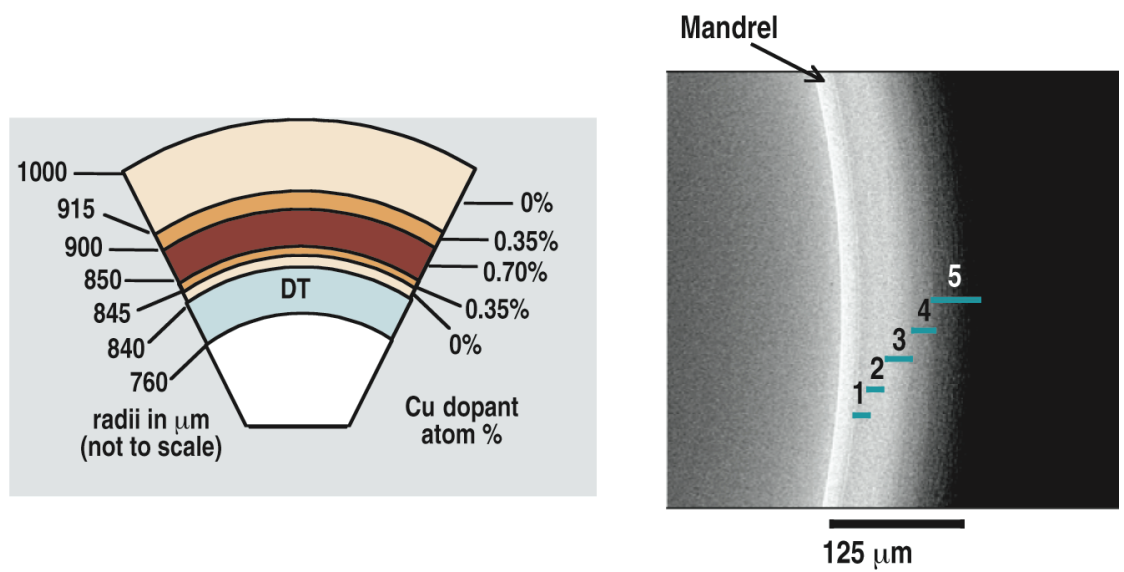

Fig. 1. Design of a graded dopant Be ignition capsule and a radiograph of a sputter-coated capsule with dopant layers.

By co-sputtering $\mathrm{Cu}$ and $\mathrm{Be}$ from sputter sources onto a thin plastic mandrel with separately controllable sputtering rates for each source, we were able to produce these layered capsules as seen in the contact radiograph in Fig. 1. These radiographs can be analyzed to allow precise (submicron) location of edges and quantification of the $\mathrm{Cu}$ concentration to about $10 \%$. Details of the materials morphology, precision radiographic analysis, effects of sputter process parameters, etc., can be found in the paper of A. Nikroo et al., this conference [3]. A lingering characteristic of sputter coating of beryllium on small spherical mandrels is the resulting micro-columnar structure and the presence of nano-voids leaving the material at less than full bulk density. The columnar structure by itself is not thought to be a problem since the targets are designed so that the beryllum melts early in the implosion [2]. However, large voids, which are usually associated with columnar structure, can lead to unacceptable density non-uniformities, and this must be controlled. Similarly, by glow-discharge coating $\mathrm{CH}$ polymer onto a polymer mandrel, and adding varying concentrations of tetra-methyl germaine to the monomer feed gas, we were able to produce 
polymer capsules with step-graded Ge dopants of the appropriate concentrations ( $\leq 1 \%$ atomic) and thicknesses [4]. For the case of polymer capsules in particular, small localized defects (sub-micron in height and of order ten microns in diameter) remain problematic.

\section{FILL TUBES, CONTROLLED FILING, AND LAYER CHARACTERIZATION}

The increased stability to the growth of short-wavelength Legendre surface modes in graded-doping capsules allows the use of ten micron-scale fill tubes through which the D-T fuel can be condensed. Details of the modeling of the effects of these fill tubes on the implosion dynamics can be found in the paper by J. Edwards et al., this conference [5]. The basic result is that the perturbation from a $10 \mu \mathrm{m}$ diameter glass fill tube countersunk into the capsule wall through which there is a $5 \mu \mathrm{m}$ fill hole, as shown in Fig. 2, is acceptable to ignition with good yield. The fill tube is sealed in place with epoxy, and it is important to control the glue fillet. A surrogate fill tube for experimental tests of its effects on OMEGA, with the proper dimensions but on a smaller capsule is also shown.

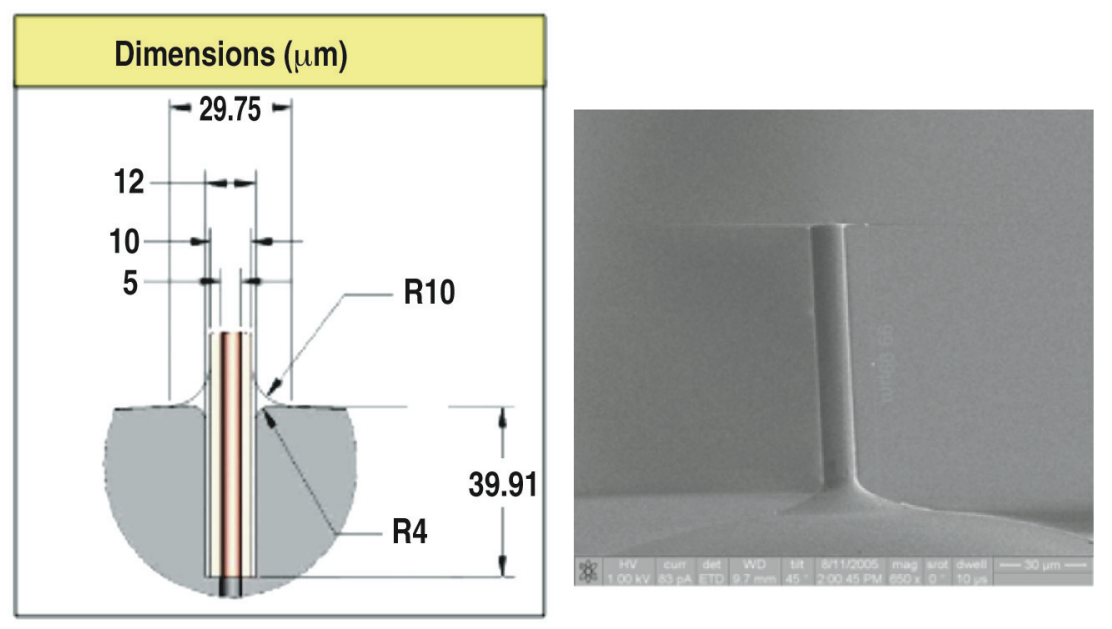

Fig. 2. Design dimensions of a micro-fill tube, with an assembled surrogate.

As described in the paper by J. Moody et al. in these proceedings [6], an indirect-drive ignition target assembly includes a small (less than $1 \mathrm{cc}$ ) D-T fuel reservoir in the target base, where it attaches to the support cryostat. This reservoir is filled with a few bars of D-T gas at room temperature, comprising a total of less than $5 \mathrm{Ci}$. By controlling the temperature of this reservoir in the range between 50 and $100 \mathrm{~K}$, with the capsule in its hohlraum held around $18 \mathrm{~K}$, the amount of D-T that condenses into the capsule can be carefully controlled. Experiments completed by Sanchez and Burman demonstrated exquisite control as shown in the data of Fig. 3. Since it is easy to control the reservoir to within $0.1 \mathrm{~K}$, the fuel layer thickness can be controlled to $0.1 \mu \mathrm{m}$, whereas the requirement is $1 \mu \mathrm{m}$.

The liquid in Fig. 3 is readily visible through the transparent polymer capsule through optical microscopy. This is not applicable to beryllium, which is optically opaque but transparent to $\mathrm{x}$-rays. Prior to a few years ago, x-rays were not considered a good fuel layer characterization tool because those 


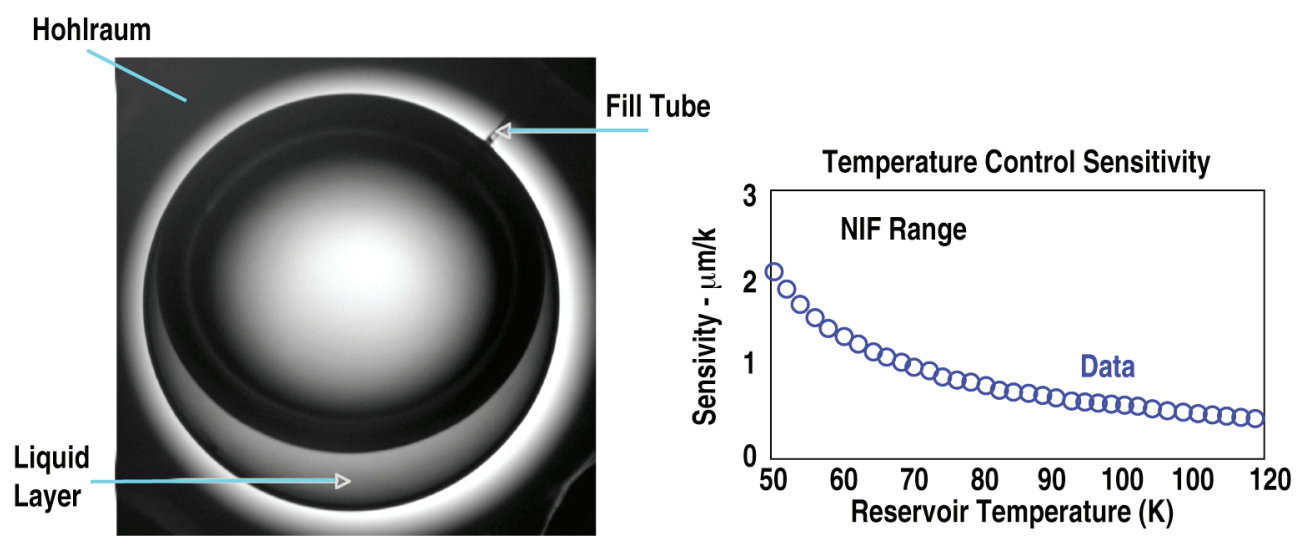

Fig. 3. Liquid D2 condensed into a polymer capsule through a tiny fill tube, and the resulting sensitivity to the control of an equivalent solid layer thickness. In the thickness range for NIF ignition, the sensitivity is about $1 \mu \mathrm{m} / \mathrm{mK}$.

energetic enough to pass through the beryllium were essentially not absorbed in solid D-T, thus making conventional radiography useless. However, it was realized that phase-contrast x-ray radiography, such as is applied to soft-tissue specimens in the medical and biological fields, would be applicable. Through a very productive collaboration between workers at Lawrence Livermore and Los Alamos National Laboratories, this has now been demonstrated. Details of the technique and results are given in the paper by D. Montgomery in these proceedings [7], as well as elsewhere. Figure 4 shows a liquid meniscus of D-T in a beryllium capsule, which, when cooled below the triple point, forms a solid that distributes into a uniform layer on the interior of the capsule by a process known as beta layering. This typically takes a few hours, and the cooling must be done slowly and carefully, or an irregular solid layer will form.
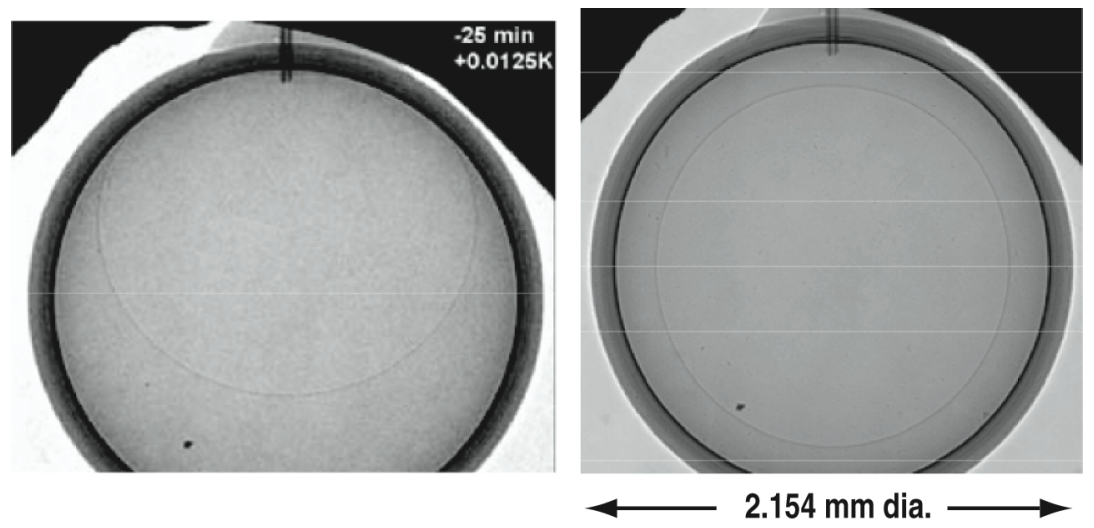

Fig. 4. Phase-contrast radiographs of liquid D-T condensed into a beryllium capsule, which upon careful cooling forms a solid layer by beta-layering.

The phase-contrast radiograph of Fig. 4 can be analyzed by methods similar to optical shadowgraphy to determine the surface modes on the ice inner surface, and it is found that the departures from perfect sphericity are small enough that this layer would ignite, even at $1.5 \mathrm{~K}$ below the triple point which is the 
design temperature. However, further cooling shows that the layer deteriorates, and the defects are readily visible with the phase contrast method. As a matter of fact, many of the optical problems associated with shadowgraphy are absent with phase-contrast radiography, and small features on the ice are in general more clearly observable.

\section{COCKTAIL HOHLRAUMS}

It has long been known that $\mathrm{x}$-ray penetration into the wall of a hohlraum is a large energy loss in the conversion of high intensity laser light to $\mathrm{x}$-rays to drive the implosion of indirect-drive capsules. It was also understood a decade ago that combinations of materials such as gold and uranium for the hohlraum wall would reduce this loss by plugging the opacity holes that exist for a single element hohlraum [8]. However, many of the proposed material combinations in these "cocktail" hohlraums are unstable, being in most cases non-equilibrium mixtures in highly stressed states and subject to rapid degradation by oxidation in normal room air. In particular, simultaneous co-sputtering of $\mathrm{Au}$ and $\mathrm{U}$ onto a copper mandrel and subsequent dissolving of the mandrel, for instance, leads to high stress and rapid deterioration. An approach that somewhat ameliorates these problems is to coat the mandrel with very thin alternating layers of the cocktail materials. The inner and outer surfaces of the hohlraum are both coated with gold which is a permeation barrier for oxygen and prevents oxidation. This is doubly important because oxidation not only cause the material to become brittle and crumble, but the presence of oxygen undoes much of the benefit of the mixture since it adds heat capacity to the hohlraum wall -i.e., more energy is needed to get the wall up to the design temperatures $(\sim 300 \mathrm{eV})$ with oxygen present.

The detailed method for producing the cocktail hohlraums is published elsewhere [9]. Very briefly, hohlraum mandrels are held in rotating fixtures and alternately exposed to the material flux from multiple sputter guns with alternating composition. By this technique, $30 \mathrm{~nm}$ layers of depleted uranium are alternated with $8 \mathrm{~nm}$ of gold to yield a $75 \% \mathrm{U} / 25 \% \mathrm{Au}$ cocktail. The hohlraum mandrel in this case is plexiglass, which can be dissolved in organic solvents rather than aqueous acids which can exacerbate oxidation. Figure 5 shows an SEM image of a layered cocktail wall cross section, and EDX analysis of the alternating composition. Neither the gold nor the uranium exactly go to zero in the EDX measurements because there is some interdiffusion of the two elements, but this is not important to either the structural integrity nor the x-ray production efficiency of the hohlraum.

\section{CONCLUSIONS}

Rapid progress has been made in developing techniques to fabricate and characterize new features of indirect-drive ignition target components. New designs with graded dopant ablators have been fabricated with both beryllium and polymer capsules, and micro-fill tubes and fill holes have been developed at the prototype level. Control of the fuel fill with fill tubes has been shown to be excellent. Cocktail holraums with good stability against oxidation and stress-induced warping have been fabricated. These developments go a long way toward reducing risk of achieving ignition on the NIF, and reducing the costs of doing so. 


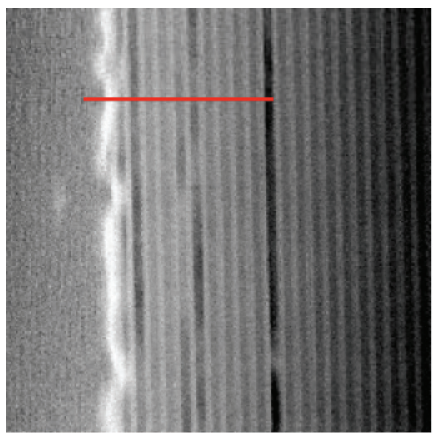

SEM Image

$8 \mathrm{~nm}$ Au Layers

Alternating with $30 \mathrm{~nm} \mathrm{U}$

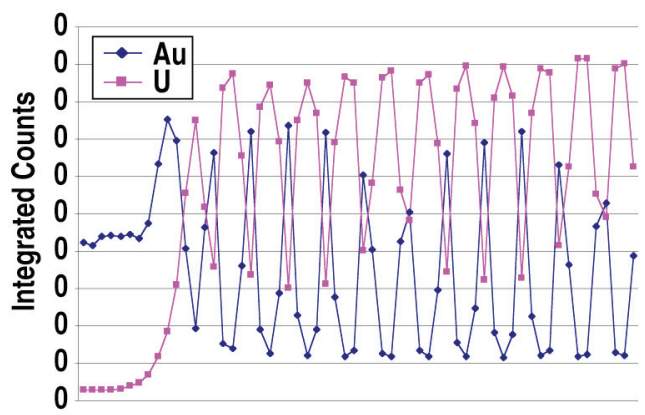

EDX Analysis of Layers

Fig. 5. Au/U cocktail hohlraum wall analysis, showing clearly distinct alternating layers.

\section{Acknowledgment}

Work supported by the U.S. Department of Energy under Contract No. DE-AC03-01SF22260.

\section{References}

[1] J. Lindl, "Recent advances in indirect drive target designs for ignition on the NIF", these proceedings. [2] S. Haan, "Update on design simulations for NIF ignition targets, and for rollup of all specifications into an error budget", these proceedings.

[3] A. Nikroo, et al, "Progress towards fabrication of graded copper doped beryllium capsules for the National Ignition Facility", these proceedings.

[4] PLEASE SUPPLY REFERENCE.

[5] J. Edwards, et al., "Ignition capsule ablator stability", these proceedings.

[6] J. Moody, et al., "Status of cryogenic layering for NIF ignition targets", these proceedings.

[7] D. Montgomery et al., "Characterization of D-T cryogenic layer formation in a Be capsule using X-ray phase contrast imaging", these proceedings. Also D.S. Montgomery et al., Rev. Sci. Instrum. 75, 3986 (2004), and B. Kozioziemski et al., J. Appl. Phys. 97, 063103 (2005).

[8] T.J. Orzechowski et al. Phys. Rev. Lett. 77, 3545 (1996).

[9] H.I. Wilkens et al., "Progress in Coating Multi-Layered Cocktail Hohlraums," Proceedings of the 16th Target Fabrication Specialist's Meeting, submitted to Fusion Sci. Technol. (2005). 